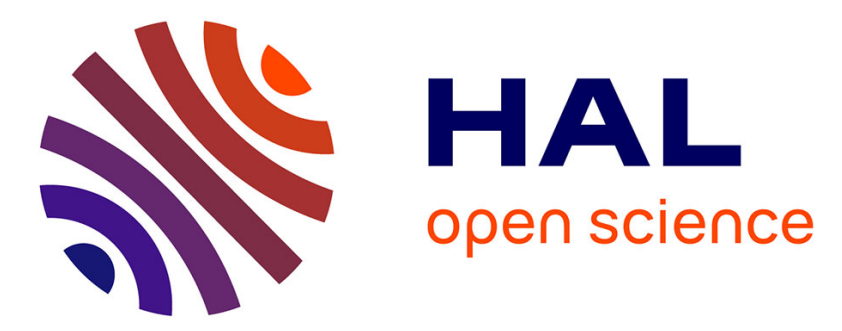

\title{
Identifying a motivational process surrounding adherence to exercise and diet among adults with type 2 diabetes
}

\author{
Manon Laroche, Peggy Roussel, Francois Cury
}

\section{To cite this version:}

Manon Laroche, Peggy Roussel, Francois Cury. Identifying a motivational process surrounding adherence to exercise and diet among adults with type 2 diabetes. Physician and Sports Medicine, 2020, 48 (1), pp.68-74. 10.1080/00913847.2019.1632154 . hal-03545170

\author{
HAL Id: hal-03545170 \\ https://hal.science/hal-03545170
}

Submitted on 27 Jan 2022

HAL is a multi-disciplinary open access archive for the deposit and dissemination of scientific research documents, whether they are published or not. The documents may come from teaching and research institutions in France or abroad, or from public or private research centers.
L'archive ouverte pluridisciplinaire HAL, est destinée au dépôt et à la diffusion de documents scientifiques de niveau recherche, publiés ou non, émanant des établissements d'enseignement et de recherche français ou étrangers, des laboratoires publics ou privés.

\section{(이) $\$$}

Distributed under a Creative Commons Attribution - NonCommercial - NoDerivatives| 4.0 


\section{ABSTRACT}

Objectives. This paper aims to provide physicians with knowledge about the motivational processes surrounding exercise and diet for patients with type 2 diabetes and to offer patient support measures to favor self-management. To respond to this objective, the links between two kind of motivators (i.e., promotion and prevention foci), the Selection, Optimization and Compensation (SOC) self-management strategy, and adherence to exercise and diet of patients with type 2 diabetes were investigated for the first time in the literature.

Method. A cross-sectional study was conducted with 491 French volunteer participants with type 2 diabetes diagnosed for at least 3 months $($ Age $=61.66 \pm 9.63 ; \mathrm{BMI}=29.8 \pm 5.9$ ). Participants completed an online self-report survey measuring SOC strategy, promotion and prevention foci, and adherence to exercise and diet.

Results. The main results of path and bootstrapping analysis demonstrated that promotion focus was positively related with SOC strategy $(\beta=.69, \mathrm{p}<.001)$ whereas prevention focus was not $(\beta=-.01, n s$.$) . On the other hand, SOC strategy was positively related with exercise$ $(\beta=.20, p<.05)$, general diet $(\beta=.49, \mathrm{p}<.001)$, fruit and vegetable consumption $(\beta=.27, \mathrm{p}$ $<.001)$, and spacing of carbohydrates $(\beta=.40, \mathrm{p}<.001)$, and mediated the positive link between promotion focus and these behaviors (bootstrapped 95\% CI: $[.11 ; .40],[.52 ; .81]$, $[.22 ; .54],[.37 ; .70]$, respectively).

Conclusion. This paper addresses a gap in previous research by evidencing a motivator that promotes self-management for exercise and diet among patients with type 2 diabetes. Our results suggest that physicians should privilege an interaction with patients oriented toward promotional motivation so as to favor their patients' self-management regarding exercise and diet. 


\section{INTRODUCTION}

Diabetes is one of the most common metabolic disorders in the world [1]. In France, there are an estimated 3 million patients with diabetes. The most common is type 2 diabetes, accounting for $>90 \%$ of all diabetes cases [2]. Exercise and diet are key aspects of its treatment $[3,4]$. Indeed, exercise and weight loss have both been shown to decrease insulin resistance and to improve glycemic control $[5,6]$, which in turn is associated with lower risk of short-term complications (e.g., hyperglycemia), long-term comorbid conditions (e.g., cardiovascular diseases), and mortality [7,8]. However, exercise and diet are perceived as costly in terms of time, organization, and personal investment [9]. Nadeau [10] underlines that "in clinical practice only a small percentage of the population with T2DM is sufficiently selfmotivated to undertake a rigorous exercise and diet program" (p.50). While physicians are aware of the importance of the patient's self-management in his/her treatment, the author stresses the lack of precise information about the motivators that promote exercise and diet in the patient.

The overall objective of this paper is thus to provide physicians with knowledge about the motivational processes surrounding exercise and diet for patients with type 2 diabetes and offer methods of support to favor their patients' self-management (e.g., What message should they privilege? What should be emphasized in patient support?)

To take exercise and follow a diet effectively, type 2 diabetes patients must be capable of making decisions and setting themselves targets appropriate to the constraints they face. This capacity to adapt to constraints and to reduced personal resources refers to a psychological process formalized by the theoretical model of Selective Optimization and Compensation (SOC, [11]). This model proposes that the combined use of four strategies helps individuals to optimally allocate their limited resources $[11,12]$ : elective selection (i.e., developing and committing to a hierarchy of personal goals), optimization (i.e., engaging in goal-directed 
actions and means), loss-based selection (i.e., changing the goal or the goal system) and compensation (i.e., acquiring alternative means in response to a loss). Several studies have shown that the use of SOC strategy has a positive influence on health behaviors such as the exercise participation of individuals in orthopedic rehabilitation [13] or older women's longterm adherence to a program of exercise [14]. In the light of these works, it could be supposed that the use of this SOC strategy would be favorable to exercise and diet among patients with type 2 diabetes. So far as we know, no study has so far examined the links between SOC strategy and exercise and diet among patients with type 2 diabetes. The first aim of this study is therefore to examine these links in this population.

On the other hand, our second aim is to identify for the first time in the literature the motivators which favor the use of this adaptative strategy. Regulatory Focus Theory [15], a well-established motivational model to study health behaviors both among healthy $[16,17,18]$ and patients with type 2 diabetes [19], identifies two kinds of motivational orientations that guide people in their self-care behaviors. The first called "promotion focus" is associated with growth and accomplishment needs [15]. In a health-related context, it is reflected by concerns for improving the health state or attaining health-related gains $[16,20]$. The second called "prevention focus" is associated with security and safety needs [15]. In a health-related context, it is reflected by concerns for protecting health state or avoiding health-related losses $[16,20]$.

In this paper, we consider that promotion focus could be a motivator favorable to the use of the SOC strategy. First, promotion-focused individuals tend to engage a flexible cognitive process [21] which is compatible with the development of new goals in response to difficulties, refinement of goal-relevant means, and acquisition of new skills/resources emphasized by the SOC strategy [12]. Secondly, SOC strategy provides guidance toward success [22], which is a goal congruent with promotion focus [23]. Thirdly, Baltes et al. [22] 
have shown in a work context that promotion focus is a positive predictor of SOC strategy. On the other hand, we propose that prevention focus would be either not or negatively associated with the adoption of SOC strategy. Prevention-focused individuals tend to engage a rigid cognitive process and not to persist for long in a difficult task [21]. These two inclinations are likely not to be compatible with the flexibility and the tenacity required by the SOC strategy [12]. Finally, given that promotion focus has been found to be a motivational orientation favorable to exercise and diet among both healthy patients [16,17] and patients with type 2 diabetes [19], the following specific mediational hypothesis was tested. We predicted that the positive relation between promotion focus, exercise and diet would be mediated by the use of SOC strategy.

In sum, in this paper our three main hypotheses are:

H1: SOC strategy should be positively associated with exercise and diet behaviors.

H2: promotion focus should be positively associated with SOC strategy whereas prevention focus should be either not or negatively associated with this variable.

H3: promotion focus should be indirectly positively associated with exercise and diet through SOC strategy

\section{METHOD}

\subsection{Procedure}

Data were collected via a cross-sectional online self-report survey. Questionnaires were mailed by a polling institute (Dynata, https://www.dynata.com, ISO 20252:2019) to a sample of French adults with type 2 diabetes constituted on a voluntary basis. Participants were treated in accordance with the ethical requirements of the Declaration of Helsinki and the French Psychological Society with respect to consent, confidentiality, and anonymity of the 
answers. Prior to data collection, all participants signed an informed consent form. They were informed of the goal of the study and of their right to stop their participation at any time. The responses were anonymous, as the individuals were only identified by the day and time of completion of the questionnaire. Prior to data collection, the study was approved by the CNIL (no. 1545711).

\subsection{Participants}

To be eligible for the study participants had to: (i) be older than 18 , (ii) have a history of at least three months of diagnosed type 2 diabetes mellitus, and (iii) have French-reading abilities. A total of 491 participants (311 men) aged from 26 to $86(M=61.7, \mathrm{SD}=9.6)$ were selected in the study. Most of the participants (93.3\%) had completed secondary education, $56 \%$ were retired, and $67.6 \%$ lived with a partner. About $72 \%$ of the participants were treated with diabetic oral medications, $22 \%$ used insulin, and $30 \%$ were not medicated for their diabetes. The average number of comorbidities per participant was 1.48 ( $\mathrm{SD}=1.96)$; the most common was arterial hypertension $(44.8 \%)$. The average body mass index of the sample was $29.8(\mathrm{SD}=5.9)$. Demographic characteristics and health condition of the sample are presented in Table 1.

\subsection{Measures}

SOC strategy. Reuter et al.'s [24] questionnaire, a version of Freund and Baltes' [12] original questionnaire adapted for leading a healthy lifestyle, was used to assess participants' SOC strategy. Using a standard "forward-backward" translation procedure, the English-language version of the questionnaire was translated into French. The questionnaire is composed of a total of four items assessing SOC strategy (e.g., "I have defined my goals exactly and stick to them"). Participants responded on a scale from $1=$ "completely disagree" to $4=$ "completely agree". 
Regulatory focus. Gomez et al.'s [20] French regulatory focus questionnaire was used to assess participants' regulatory focus. This questionnaire is composed of a total of eight items which assess regulatory focus in the health-specific context: five items assessing promotion focus (e.g., "I do not hesitate to embrace new experiences if I think they can improve my health"), and three items assessing prevention focus (e.g., "I frequently think about the health problems I may have in the future"), presented in a random order. Participants responded on a scale from $1=$ "completely disagree" to $7=$ "completely agree". Because a previous study [25] has shown that a prevention focus item (i.e., "When I implement a health behavior, it's because I want to protect myself from getting sick") exhibited unsatisfactory psychometric properties, this item was slightly adjusted.

Exercise and diet diabetes self-care behaviors. The exercise and diet subscales of the Summary of Diabetes Self-Care Activities questionnaire (SDSCA, [26]) were used to assess participants' adherence to exercise and diet. Using a standard "forward-backward" translation procedure, the English-language version of the items was translated into French. Respondents are requested to indicate on how many days of the week (0-7) they performed each activity when they were not sick. Two items assessed adherence to exercise behavior (e.g., "Did you participate in at least 30 minutes of physical activity?"), two items assessed adherence to general diet (e.g., "Have you followed a healthful eating plan?"), and three items assessed adherence to three specific diet behaviors (i.e., "Did you eat five or more servings of fruits and vegetables?", "Did you eat high-fat foods such as red meat or full-fat dairy products?", "Did you space carbohydrates evenly through the day?"). As recommended by Toobert et al. [26], responses to the item related to high-fat food consumption were reversed $(0=7,1=6$, $2=5,3=4,4=3,5=2,6=1,7=0)$.

\subsection{Statistical analysis}


First, the reliability of each measure was examined. For SOC strategy and Regulatory focus measures, two confirmatory factorial analyses (CFA) were performed on the covariance matrix of the items to examine whether the factorial structures delineated by Gomez et al. [20] and Reuter et al. [24] generated adequate fit with the observed data. A model was considered adequate if the comparative fit index (CFI) and the goodness of fit index (GFI) were greater than or equal to .90 , and if the root mean square residual (RMSEA) was lower than or equal to .08 [27]. In addition, for all measures (i.e., SOC strategy, Regulatory focus, and Exercise and diet diabetes self-care behaviors) the internal consistency of the items was examined. The internal consistency could be considered satisfactory when Cronbach alphas < 65 [28].

Once the reliability of the measurements was verified the descriptive statistics (mean, standard deviation, distribution) and correlations of the key variables were examined. Then, a path model for evaluating the combined contribution (direct and indirect effects) of each variable - SOC strategy, promotion focus, prevention focus - on exercise, general diet, fruit and vegetable consumption, high-fat food consumption, and spacing of carbohydrates was run. In this model, age, gender, number of comorbidities and educational level were included as control variables. This path analysis was conducted by using Lisrel 9.1. The .05 level of significance was used for all statistical hypothesis testing. Beta represents the standardized regression coefficient. As for previous analyzes, the recommendations of Meyers et al. [27] were applied to assess the adequacy of the model (CFI and GFI $\geq .90$; RMSEA $\leq .08$ ). Finally, using SPSS software 18.0, a bootstrapping method [29] resample set at 5000 samples with bias-corrected $95 \%$ confidence intervals was employed to test the significance of the indirect effects. Point estimates of indirect effects are considered significant when zero is not contained in $95 \%$ confidence intervals [29].

\section{RESULTS}




\subsection{Reliability of the measures}

SOC strategy. The results of the CFA showed that the one-factor model delineated by Reuter et al. [24] provided an excellent fit with the data: $\chi^{2} / d f=1.96$; $\mathrm{RMSEA}=.04 ; \mathrm{GFI}=1 ; \mathrm{CFI}=$ 1. Internal consistency was satisfactory $(\alpha=.88)$. An average score was thus computed for SOC strategy.

Regulatory focus. The results of the CFA showed that the two-factor model delineated by Gomez et al. [20] provided a good fit with the data: $\chi^{2} / d f=4.13$; RMSEA $=.08$; GFI $=.96$; CFI $=.98$. Internal consistency was satisfactory for both the promotion focus $(\alpha=.86)$ and prevention focus $(\alpha=.85)$ subscales. Average scores were thus computed for each regulatory focus.

Exercise and diet diabetes self-care behaviors. Internal consistency was satisfactory for both exercise $(\alpha=.68)$ and general diet $(\alpha=.96)$ subscales. The mean number of days was thus computed for each of these subscales. However, the internal consistency value for the three items of the specific diet subscale was low $(\alpha=.32)$. This low consistency did not allow us to average the scores of these three items. This result is similar to that obtained by Toobert et al. [26]. In accordance with these authors' procedure, the items were examined separately in the subsequent analyses.

\subsection{Descriptive analyses}

Means, standard deviations, and Pearson's correlation coefficients for the variables are presented in Table 2. Pearson's correlations showed that (i) SOC strategy was positively correlated with exercise, general diet, fruit and vegetable consumption, and spacing of carbohydrates, and was not correlated with high-fat food consumption; (ii) promotion focus was positively correlated with SOC strategy, exercise, general diet, fruit and vegetable consumption, and spacing of carbohydrates, and was not correlated with high-fat food 
consumption; and (iii) prevention focus was not correlated with SOC strategy, slightly positively correlated with exercise, general diet, and spacing of carbohydrates, and was not correlated either with fruit and vegetable consumption or high-fat food consumption. The results of the distribution analyses (see Table 3) show that skewness and kurtosis coefficients are respectively $< \pm 2$ and $< \pm 7$ for all the variables. In accordance with the recommendations of Tabachnick and Fidell [30], the normality of the distribution of our sample was thus verified for all the variables. For each variable, the proportion of the sample having checked the minimum of the scale was relatively low. Thus, our participants were relatively concerned by SOC strategy, Regulatory focus, and Exercise and diet diabetes self-care behaviors.

\subsection{Hypothetical model path analysis}

The hypothetical path model provided a good fit to the data $\left(\chi^{2}=107.1 ; \mathrm{df}=25 ; \chi^{2} / d f=4.28\right.$; RMSEA $=.08 ;$ GFI $=.96$; CFI $=.93$ ). The results indicated that when controlling age, gender, number of comorbidities, and educational level, SOC strategy was positively related with exercise $\left(\beta=.20, p<.05, R^{2}=.15\right)$, general diet $\left(\beta=.49, p<.001, R^{2}=.24\right)$, fruit and vegetable consumption $\left(\beta=.27, \mathrm{p}<.001, \mathrm{R}^{2}=.10\right)$, and spacing of carbohydrates $\left(\beta=.40, \mathrm{p}<.001, \mathrm{R}^{2}\right.$ $=.18)$, and not related with high-fat food consumption $\left(\beta=-.03, n s ., \mathrm{R}^{2}=.02\right)$.

On the other hand, promotion focus was positively related with SOC strategy $(\beta=.69, \mathrm{p}$ $\left.<.001, \mathrm{R}^{2}=.49\right)$ whereas prevention focus was not associated with this variable $(\beta=-.01, n s$.$) .$ Finally, bootstrapping analyses indicated that promotion focus was indirectly related positively with exercise (point estimate of .07 , bias-corrected bootstrapped $95 \%$ CI of .11 to .40 ), general diet (point estimate of .08 , bias-corrected bootstrapped $95 \%$ CI of .52 to .81 ), fruit and vegetable consumption (point estimate of .08, bias-corrected bootstrapped $95 \%$ CI of .22 to .54 ), and spacing of carbohydrates (point estimate of .09 , bias-corrected bootstrapped $95 \%$ CI of .37 to .70$)$ through SOC strategy. SOC strategy partially mediated the direct link between promotion focus and exercise $(\beta=.15, \mathrm{p}<.05)$, and totally mediated the direct links 
between promotion focus and general $\operatorname{diet}(\beta=-.03, n s$.$) , fruit and vegetable consumption ( \beta$

$224=.03, n s$.$) , and spacing of carbohydrates (\beta=-.02, n s .)^{1}$. Significant indirect relations are

225 illustrated in Figure 1.

\section{DISCUSSION}

228 The overall objective of this study was to provide physicians with knowledge about motivational processes favoring self-management for exercise and diet among patients with type 2 diabetes. First, as hypothesized, the results show that SOC strategy is positively related with exercise and most diet behaviors (including general diet, consumption of fruit and vegetables and spacing of carbohydrates). For the first time in the literature, these results show thus that SOC strategy is beneficial for exercise and diet in patients with type 2 diabetes and extend the work done on other populations (e.g., patients in orthopedic rehabilitation, [13]; older women, [14]). Furthermore, for physicians, they suggest that the SOC selfmanagement strategy (i.e., selecting and planning one's objectives by order of priority, assigning the necessary time and effort for the fulfilment of those objectives, adapting one's level of demand if difficulties arise) should be privileged in order to promote exercise and diet in this population.

Secondly, as hypothesized, the results of this study show that (i) promotion focus is positively related with SOC strategy whereas prevention focus is not and (ii) promotion focus is 242 positively related with exercise and most diet behaviors through the SOC strategy. For the

243 first time in the literature, these results thus identify a motivational determinant of the SOC

\footnotetext{
${ }^{1}$ The effects of diabetes duration and diabetes treatment (no treatment vs. insulin vs. oral medication) were also checked in complementary analyses. The results of structural analyses showed that diabetes duration was not associated with exercise, nor with general diet, fruit and vegetable consumption, high-fat food consumption, or spacing of carbohydrates. On the other hand, the results of ANOVAs showed that diabetes treatment had no effect on exercise, general diet, fruit and vegetable consumption, or high-fat food consumption. However, patients with insulin as diabetes treatment reported more spacing of carbohydrates than patients with oral medication. Given this result, we therefore compared the contribution of promotion focus, prevention focus, and SOC strategy on spacing of carbohydrates in these two sub-groups. The results of these analyses indicated that whatever the group, SOC strategy was positively associated with spacing of carbohydrates, promotion focus was positively associated with spacing of carbohydrates through SOC strategy, and prevention focus was not associated with SOC strategy.
} 
strategy used among patients with type 2 diabetes for exercise and diet. In addition, they extend the study of Avraham et al. [19] by documenting a process in the positive link between promotion focus, exercise and diet among patients with type 2 diabetes. In so doing, they advance knowledge about the consequences of promotion focus, and provides perhaps the most detailed and specific explanation to date of the promotion focus-health behaviors relation. Furthermore, the identification of this motivator favorable to the use of the SOC strategy to promote exercise and diet makes it possible to advise physicians on what should be prioritized in patient support to favor their patients' self-management. Specifically, physicians can encourage their patients' self-management by guiding them towards promotion rather than a prevention motivation.

Concretely, in terms of methods of support (e.g., arguments to be highlighted in a therapeutic education program, interactions with patients), it first implies that physicians should adopt a positive motivational discourse centered on the health benefits of exercise and diet (e.g., "Take exercise and eat healthily to improve your quality of life", "Go ahead with exercise and healthy eating") rather than an alarmist discourse focused on the risks of complications (e.g., "Take exercise and keep to a diet to avoid worsening your state of health", "Keep active and eat healthily to avoid complications linked to diabetes"). Such alarmist discourse may be effective among patients with type 2 diabetes in promoting other self-care behaviors such as medication [20, 18], but it does not favor exercise and adopting a healthy diet. To guide patients towards a motivational orientation promotion, physicians could also encourage them to focus on their progress and success in their exercise and diet (e.g., stressing the progress made, setting new targets for moving forward). By privileging this type of motivation, physicians should enable their patients to be more capable of self-managing in their treatment behaviors and so facilitate their adherence to constraining health behaviors such as exercise and diet. 


\section{Limitations}

271 Despite the scope of these results, both theoretically and practically, some limitations of the study should be mentioned. First, the cross-sectional design of the study does not allow for causal claims among the variables. Future experimental study should thus confirm the effects of promotion focus on exercise and diet through SOC strategy. In addition, future longitudinal studies on patients with type 2 diabetes could strengthen our study by examining, over a year for example and with different measuring times, the long-term impact of promotion focus on exercise and diet, since these are two health behaviors that are beneficial when practiced over the long term. The question of maintenance over time is therefore essential. Thirdly, the results of this study show that high-fat food consumption was not related either with promotion focus or with SOC strategy. This result is not consistent with those obtained with other items assessing diet (i.e., general diet, consumption of fruits and vegetables, and spacing of carbohydrates). Previous research also did not find the results expected regarding high-fat food consumption [31,32]. Gonzales et al. [31] state that the item of the SDSCA products' as the only two examples of high-fat foods. This item may not capture other sources of high-fat (e.g. fried foods, fast food)" (p.1105). Future research should analyze high-fat food consumption behavior in relation to promotion focus more closely by capturing other high-fat foods. Finally, glycemic control was not measured in this study. A further study examining to what extent regulatory foci and SOC strategy are related to exercise and diet behaviors by controlling the potential effect of glycemic control could complement our present results.

\section{CONCLUSION}


Beyond these limitations, these findings contribute to the literature in health psychology by evidencing for the first time among patients with type 2 diabetes (i) positive links between SOC strategy and adherence to exercise and diet, (ii) motivators of SOC strategy, and (iii) a specific process underlying the link between promotion focus and adherence to exercise and diet. In addition to these theoretical implications, this study also suggests practical steps for physicians about motivators that promote self-management for exercise and diet among patients with type 2 diabetes. Physicians should privilege an approach to patients oriented towards promotional motivation so as to favor self-management regarding exercise and diet.

\section{REFERENCES}

1. Guariguata L, Whiting DR, Hambleton I, et al. Global estimates of diabetes prevalence for 2013 and projections for 2035. Diabetes Res Clin Pract. 2014;103(2):137-149.

2. Mandereau-Bruno L, Fosse-Edorh S. Prévalence du diabète traité pharmacologiquement (tous types) en France en 2015. Disparités territoriales et socio-économiques. [Prevalence of pharmacologically treated diabetes (all types) in France in 2015. Territorial and socioeconomic disparities]. Bull Epidémiol Hebd. 2017;(27-28):586-91. French.

3. Colberg SR, Sigal RJ, Yardley JE, et al. Physical activity/exercise and diabetes: a position statement of the American Diabetes Association. Diabetes Care. 2016;39(11):2065-2079.

4. Evert AB, Boucher JL, Cypress M, et al. Nutrition therapy recommendations for the management of adults with diabetes. Diabetes Care. 2013;36(11):3821-3842.

5. Snowling NJ, Hopkins WG. Effects of different modes of exercise training on glucose control and risk factors for complications in type 2 diabetic patients: a meta-analysis. Diabetes Care. 2006;29(11):2518-2527. 
6. Espeland M. Reduction in weight and cardiovascular disease risk factors in individuals with type 2 diabetes: one-year results of the look AHEAD trial. Diabetes Care. 2007;30(6):1374-1383.

7. Andersson DKG, Svärdsudd K. Long-term glycemic control relates to mortality in type II diabetes. Diabetes Care. 1995;18:1534-1543.

8. Klein R, Klein BEK, Moss SE: relation of glycemic control to diabetic microvascular complications in diabetes mellitus. Ann Intern Med. 1996(1_Part_2);124:91-96.

9. Booth AO, Lowis C, Dean M, et al. Diet and physical activity in the self-management of type 2 diabetes: barriers and facilitators identified by patients and health professionals. Prim Health Care Res Dev. 2013;14(3):293-306.

10. Nadeau DA. Management of type 2 diabetes mellitus in self-motivated patients: optimized diet, exercise, and medication for weight loss and cardiometabolic fitness. Phys Sportsmed. 2014;42(4):49-59.

11. Baltes PB, Baltes MM. Successful aging: Perspectives from the behavioral sciences. New York (NY): Cambridge University Press; 1990. Chapter 1, Psychological perspectives on successful aging: The model of selective optimization with compensation; p. 1-34.

12. Freund AM, Baltes PB. Life-management strategies of selection, optimization and compensation: Measurement by self-report and construct validity. J Pers Soc Psychol. 2002;82(4):642-662.

13. Ziegelmann JP, Lippke S. Planning and strategy use in health behavior change: A life span view. Int J Behav Med. 2007;14(1):30-39.

14. Evers A, Klusmann V, Ziegelmann JP, et al. Long-term adherence to a physical activity intervention: the role of telephone-assisted vs. self-administered coping plans and strategy use. Psychol Health. 2012;27(7):784-797.

15. Higgins ET. Beyond pleasure and pain. Am Psychol. 1997;52(12):1280-1300. 
16. Ferrer RA, Lipkus IM, Cerully J, et al. Developing a scale to assess health regulatory focus. Soc Sci Med. 2017;195:50-60.

17. Joireman J, Shaffer MJ, Balliet D, et al. Promotion orientation explains why futureoriented people exercise and eat healthy: Evidence from the two-factor consideration of future consequences-14 scale. Pers Soc Psychol Bull. 2012;38(10):1272-1287.

18. Leder S, Florack A, Keller J. Self-regulation and protective health behaviour: how regulatory focus and anticipated regret are related to vaccination decisions. Psychol Health. 2015; 30(2):165-88.

19. Avraham R, Van Dijk D, Simon-Tuval T: regulatory focus and adherence to self-care behaviors among adults with type 2 diabetes. Psychol Health Med. 2016;21(6):696-706.

20. Gomez P, Borges A, Pechmann CC: avoiding poor health or approaching good health: Does it matter? Conceptualization, measurement and consequences of health regulatory focus. J Consumer Psychol. 2013;23(4):451-463.

21. Crowe E, Higgins ET. Regulatory focus and strategic inclinations: Promotion and prevention in decision-making. Organ Behav Hum Decis Process. 1997;69(2):117-132.

22. Baltes BB, Wynne K, Sirabian M, et al. Future time perspective, regulatory focus, and selection, optimization, and compensation: Testing a longitudinal model. J Organ Behav. 2014;35(8):1120-1133.

23. Higgins ET, Roney CJ, Crowe E, et al. Ideal versus ought predilections for approach and avoidance distinct self-regulatory systems. J Pers Soc Psychol. 1994;66(2):276-286.

24. Reuter T, Ziegelmann JP, Wiedemann AU, et al. Planning bridges the intention-behaviour gap: Age makes a difference and strategy use explains why. Psychol Health. 2010;25(7):873-887.

25. Schmalbach B, Spina R, Steffens-Guerra I, et al. Psychometric Properties of the German Version of the Health Regulatory Focus Scale. Front Psychol. 2017;8:1-10. 
26. Toobert DJ, Hampson SE, Glasgow RE: the summary of diabetes self-care activities measure: Results from 7 studies and a revised scale. Diabetes Care. 2000;23(7):943-950.

27. Meyers, LS, Gamst, G, Guarino, AJ. Applied multivariate research. Thousand Oaks (TO): Sage Publications; 2006.

28. Nunally JC. Psychometric Theory. New York (NY): Mc-Graw-Hill Book Company, 1967.

29. Preacher KJ, Hayes AF. SPSS and SAS procedures for estimating indirect effects in simple mediation models. Behav Res Methods Instrum Comput. 2004;36:717-731.

30. Tabachnick BG, Fidell LS. Using Multivariate Statistics (5th edn). Boston (MA): Pearson Education; 2007.

31. Gonzalez JS, Safren SA, Delahanty LM, et al. Symptoms of depression prospectively predict poorer self-care in patients with Type 2 diabetes. Diabet Med. 2008;25(9):11021107.

32. Sarkar U, Fisher L, Schillinger D: is self-efficacy associated with diabetes selfmanagement across race/ethnicity and health literacy? Diabetes Care. 2006;29(4):823829. 